\title{
EXPLORING THE RELATIONSHIPS BETWEEN CONSTRUCTIVIST LEARNING ENVIRONMENT AND CRITICAL THINKING ABILITY OF SECONDARY SCHOOL STUDENTS
}

\author{
Yee Wan Kwan \\ University of St Joseph (Macau SAR)
}

\begin{abstract}
Constructivist learning environments are a core instructional factor affecting students' critical thinking (Mathews \& Lowe, 2011). However, few classroom environment research have specifically investigated relationships between students' perceptions of their learning environment and their critical thinking ability (e.g., Fraser, 2012), especially in the context of Chinese learners. Therefore this study would fill this research gap by investigating the relationships between constructivist learning environments and critical thinking ability among Hong Kong secondary school students.

The study used a cross-sectional survey design to collect data from a convenience sample of 967 students studying Liberal Studies or Integrated Humanities in Secondary Three (Grade 9) in Hong Kong. The respondents completed a self-administered questionnaire which included the Constructivist Learning Environment Survey (CLES), Cornell Critical Thinking Test Level X, and demographic information on age and gender.

The findings showed that students perceived their learning environment to be moderately constructivist in nature, and scored a moderate level of critical thinking ability. Both age and school banding differences were identified in which younger and students in schools with higher banding tended to perceive a higher degree of constructivist characteristics in their learning environment and they obtained higher critical thinking ability scores. Multiple regression analyses indicated that five of the seven independent variables were predictors of critical thinking ability. Shared Control was the strongest predictor and negatively associated with critical thinking ability. Personal Relevance, Critical Voice, and Uncertainty were positively while age was negatively related to critical thinking ability. The hypothesized model of seven demographic and CLES variables accounted for $10 \%$ of variance of critical thinking ability, suggesting a medium effect size. Findings of the study are discussed with reference to developing students' critical thinking ability in classrooms.
\end{abstract}

Keywords: Constructivist learning environment, critical thinking ability, secondary school students.

\section{Introduction}

A constructivist learning environment is an environment facilitating learning so as to develop learners' own, active cognitive abilities (Yilmaz, 2008). In other words, it helps to develop reasoning, critical thinking, understanding and use of knowledge, self-regulation and mindful reflection. However, there are few classroom environment research specifically investigating the link between students' perception of their learning environment and their critical thinking ability (e.g., Fraser, 2012), especially in Hong Kong. This study would fill this research gap by investigating the associations between constructivist learning environment and critical thinking ability of Hong Kong secondary school students.

\section{Study objectives \& significance}

The purpose of this study was to investigate the relationships between constructivist learning environment and critical thinking ability among Hong Kong secondary school students. The study was guided by the following research questions:

1. What are the differences in students' perceptions of constructivist learning environment and critical thinking ability in terms of gender, age, and school banding?

2. Which of the seven variables (i.e. gender, age, and five scales of constructivist learning environment) is the most important in predicting critical thinking ability? 
The current study would fill the research gap by providing empirical data on the relationship between constructivist learning environment and critical thinking, as well as determining the important predictors of developing students' critical thinking. Results of this study would be useful for teachers when they design lessons grounded on constructivist teaching approaches to foster students' critical thinking ability.

\section{Literature review}

\subsection{Learning environment in constructivist nature}

Constructivism could be interpreted from perspectives ranged from philosophy, science education, educational psychology to instructional technology (Driscoll, 2020). From the educational perspective, it associates with instructional theories, such as collaborative learning, student-centered learning, and authentic assessment (McNichols, 1999), assuming students that are active learners and can construct knowledge for themselves.

Educators (e.g., Dryden \& Fraser, 1998; Jonassen, 1994) proposed core characteristics that reflect a constructivist learning environment. Dryden and Fraser (1998) defined constructivist learning environment as an environment in which "students should find personal relevance in their studies (Personal Relevance), share control over their learning (Shared Control), feel free to express concerns about their learning (Critical Voice), view subject knowledge as ever changing (Uncertainty), and interact with each other to improve (Student Negotiation) (p.1)". Taylor, Fraser, and White (1994) developed an instrument entitled, Constructivist Learning Environment Survey (CLES) aligned with these theoretical characteristics suggested by Dryden and Fraser (1998). There are few instruments like CLES that is explicitly and theoretically grounded on constructivism. This study would adopt it in assessing the constructivist learning environment.

\subsection{Relationships between constructivist learning environment and critical thinking}

Existing studies that investigated the influence of learning environment on critical thinking usually adopted a pre-/post-test quasi-experimental design or qualitative methods to measure the effects of the constructivist-oriented learning environment on students' critical thinking. Most of their findings showed that there was a positive relationship between constructivist-oriented learning environment and critical thinking.

However, these studies used different forms of constructivist instructional approaches. For example, Ernst and Monroe (2006) adopted a pre- and post- test design, examining the impact of environment-based education, featured with constructivist approaches, on the critical thinking of 9th and 12th grade students in the US. They found that such constructivist-oriented program improved the post-test critical thinking of both 9 th $[t(159)=3.186, p<.01]$ and 12 th grade students $[t(221)=3.657$, $p<.001]$. As observed, these studies on constructivist learning environments which might be in the forms of learner-centered learning (Ernst \& Monroe, 2006), web-based learning (Rumpagaporn, 2007), and discussion and cooperative learning (Yang, Newby, \& Bill, 2005), their conclusions of the impacts of constructivist learning environments might not refer to same characteristics of a learning environment.

Therefore, this study aimed to further understand the associations between constructivist learning environment as measured by a standardized instrument, CLES, and critical thinking ability.

\section{Study method}

\subsection{Participants}

Data were obtained from a convenience sample of 967 students who enrolled in Secondary Three (i.e., Grades 9) in seven government aided secondary schools in Hong Kong. The sample included 425 boys $(44 \%)$ and 539 girls $(56 \%)$. They aged from 14 to 18 years and the mean was 14.8 years. They were either studied Liberal Studies or Integrated Humanities.

\subsection{Instruments and data analysis}

A questionnaire was created by combining various dimensions from the Constructivist Learning Environment Survey (CLES) (Aldridge, Fraser, Taylor, \& Chen, 2000), Cornell Critical Thinking Test, Level X (CCTT-X) (Ennis, Millman, \& Tomko, 1985) to measure perceptions on constructivist learning environment and critical thinking ability respectively. A section comprising items to measure demographic information from the participants, such as age and gender, was also included in the questionnaire. The version of five-factor structure with 25 items of CLES used in this study was modified and validated by Kwan (2020). The reliability coefficients of this Chinese version of 25-item CLES 
ranged from .67 to .93 in this study, while that of the 36 -item Chinese CCTT-X in the present study was .81 , demonstrating good internal consistency.

T-tests, analyses of variance (ANOVA) and multiple regression analysis were used to determine the differences of perceptions on constructivist learning environment and critical thinking ability scores by gender, age group, and school bandings, as well as to examine the important predictors of critical thinking ability.

\section{Study results}

\subsection{Differences in constructivist learning environment and critical thinking ability by gender, age, and school banding}

The overall mean score for CLES was $3.23(\mathrm{SD}=.49)$. With the highest possible score being 5 , a mean of 3.23 was slightly above the mid-point and indicated that the students perceived their learning environment to be moderately constructivist in nature. The total mean score of students' critical thinking ability was 22.48 ( $\mathrm{SD}=6.12$ ). With the highest possible score being 36 , a mean of 22.48 was above the mid-point, demonstrating that the students also had a moderate level of critical thinking ability.

Gender differences. Results obtained from the independent-samples t-tests indicated that there was no significant gender differences in students' perceptions of their constructivist learning environment and critical thinking ability scores $(p>.05)$.

Age differences. The range for participants' age was from 14 to 18, the age group was recoded into three sub-groups: $14(\mathrm{n}=367), 15(\mathrm{n}=440)$, and 16-18 $(\mathrm{n}=138)$. Using the ANOVA, differences were found between these three age groups on the total CLES and all its scales (i.e., Personal Relevance, Uncertainty, Critical Voice, and Student Negotiation) except for the Shared Control scale. Age difference was also found on their critical thinking ability. These results suggested that younger students perceived a higher level of constructivist nature in their learning environments across a number of scales of CLES and obtained higher critical thinking scores generally $(p<.05)$.

School banding differences. Students' perceptions of the constructivist learning environment were analyzed by their school banding: Bands $1(n=241), 2(n=588)$, and $3(n=127)$. The majority of students in Band 1 schools are assumed those with the best academic results. Differences were found on the total CLES and for all of its scales with the exception of the Shared Control scale. There was school banding difference on their critical thinking ability. Students in band 1 schools tended to perceive a higher level of constructivist learning environment across a number of scales of CLES and obtained higher critical thinking scores generally than those in other school bandings $(p<.05)$.

\subsection{Predictors of critical thinking ability}

In order of determine the predictors of critical thinking ability, correlations and regression analysis were performed (Table 1). All variables were significantly correlated with critical thinking ability except gender.

Table 1. Correlation and multiple regression analyses for associations between gender, age, and constructivist learning environment and critical thinking ability.

\begin{tabular}{lccc}
\hline \multicolumn{1}{c}{ Variable } & \multicolumn{3}{c}{ Associations with critical thinking ability } \\
& $r$ & $(\mathrm{~N}=947)$ & $(\mathrm{SE})$ \\
\hline Gender (Dummy Female=0) & .05 & $\beta$ & $(.38)$ \\
Age & $-.16^{* * *}$ & $-.12^{* * *}$ & $(.24)$ \\
Personal Relevance & $.19^{* * *}$ & $.16^{* * *}$ & $(.36)$ \\
Uncertainty & $.15^{* * *}$ & $.07 *$ & $(.31)$ \\
Critical Voice & $.11^{* * *}$ & $.08^{*}$ & $(.29)$ \\
Shared Control & $-.14^{* * *}$ & $-.21^{* * *}$ & $(.25)$ \\
Student Negotiation & $.08^{* *}$ & .03 & $(.29)$ \\
$\quad \mathrm{F}$ & & $15.37 * * *$ & \\
df & & $(7,935)$ & \\
Adjusted $R^{2}$ & \multicolumn{3}{c}{}
\end{tabular}

The $\mathrm{F}$ ratio demonstrated that gender, age and the CLES scales were significantly related to students' score of critical thinking ability. Concerning the standard regression coefficients for these seven independent variables, five variables were significant predictors of critical thinking ability. The strongest 
predictor was Shared Control $(\beta=-.21, p<.001)$ but in a negative direction. Personal Relevance $(\beta=.16$, $p<.001)$, Age $(\beta=-.12, p<.001)$, Critical Voice $(\beta=.08, p<.05)$, and Uncertainty $(\beta=.07, p<.05)$ were also the predictors of critical thinking ability. Gender and Student Negotiation had no effect on critical thinking ability. According to Kline (2011), a value of $R^{2}$ about .10 represents a medium effect size. The hypothesized model of seven variables accounted for $10 \%$ of variance of critical thinking ability, indicating a medium effect size.

\section{Discussion, implications and conclusion}

Results of this study showed that (1) the students perceived their learning environment to be moderately constructivist in nature and scored a moderate level of critical thinking ability; (2) younger students and students in band 1 schools tended to perceive their learning environment to be more constructivist in nature, and obtained higher critical thinking ability scores; (3) Shared Control, Personal Relevance, Critical Voice and Uncertainty of CLES and age were significant predictors of critical thinking ability; and (4) the seven demographic and CLES variables explained $10 \%$ of variances in critical thinking ability, indicating a medium effect size.

\subsection{Discussion}

First, younger and students in band 1 schools scored higher in constructivist learning environment and critical thinking ability in this study. Constructivist approaches are believed favorable to advanced students because they are likely equipped with knowledge and strategies for them to self-construct learning in these lessons (Driscoll, 2020; Yilmaz, 2008). Since students in band 1 schools in Hong Kong are generally those with better academic achievement, so they might be ready to learn in constructivist learning approaches and eventually result in higher critical thinking ability as expected. Similarly, Alansari and Rubie-Davies (2020)'s recent review on decades of learning environment research in pre-tertiary level also pointed out that environments with positive perceptions were significantly associated with higher levels of academic performance. However, the findings of previous studies on gender difference were mixed. Like the results of the present study, Kesal and Aksu (2005)'s study with Turkish students also found that perceptions of constructivist learning environment did not differ significantly by gender. Further studies are recommended to test whether there is gender difference in perceptions of classroom environment and in what ways.

As for the relationships between CLES scales and critical thinking ability, the results showed that four (i.e., Personal Relevance, Uncertainty, Critical Voice, and Shared Control) out of the five scales were found to be the predictors of students' critical thinking ability. These findings confirmed that characteristics of the constructivist learning environment that were favorable to students' critical thinking ability. For example, higher relevance of learning content to students' daily life, allowing to express their views on current teaching plans and methods, and less sharing of control by teachers with their students in designing and managing learning activities. Interestingly, constructivist learning environment is believed to be student-centered in nature which emphasizes students' active involvement in learning and assessment activities. However, students with minimum guidance from teachers felt lost, frustrated, and confused (Brown \& Campione, 1994). Therefore, the finding of a negative relationship between Shared Control and critical thinking ability in this study might reflect such dilemma in practicing the core ideas of constructivist learning approaches. Teachers have to maintain a balance between well-planned and guided lessons by them on one hand, on the other hand they should endure flexibility to change timely so as to address students' needs and feedback.

\subsection{Significance, limitations and conclusion}

Theoretically constructivist learning environments aim at promoting critical thinking. This study filled the research gap by examining the relationship between constructivist learning environment and critical thinking ability explicitly, measuring the operationalized characteristics of the constructivist learning environment.

There are several limitations of this study. The study employed a convenience sample which might cause selection bias affecting the generalisability of the findings to a larger population. As this study focused on Secondary Three (Grade 9) students, the findings may not be generalisable to students of other grade levels. Similar studies are suggested to conduct at different education levels, in particular the tertiary education level (Alansari \& Rubie-Davies, 2020). In addition, this study explored the relationship between demographics and constructivist learning environment and critical thinking ability, other possible factors and how these factors interacted with each other on critical thinking ability were not covered. Further researches on this topic are recommended to explore different theoretical and research methodologies. 
In conclusion, there is rare study that measured the constructivist learning environment and critical thinking ability by adopting the CLES and CCTT-X, particularly in the context of Chinese learners. Hence, the findings of this research provided empirical information about their associations. This study confirmed that most of dimensions of constructivist learning environment are important and helpful to critical thinking ability. One of the findings interestingly demonstrated that Shared Control was negatively while Critical Voice was positively associated with critical thinking ability. This finding could inform teachers who use constructivist learning approaches in making the balance between teacher-dominated guidance and student-centered knowledge construction in their classrooms.

\section{References}

Alansari, M., \& Rubie-Davies, C. (2020). What about the tertiary climate? Reflecting on five decades of class climate research. Learning Environments Research, 23, 1-25.

Aldridge, J. M., Fraser, B. J., Taylor, P. C., \& Chen, C. C. (2000). Constructivist learning environments in a crossnational study in Taiwan and Australia. International Journal of Science Education, 22(1), 37- 55 .

Brown, A., \& Campione, J. (1994). Guided discovery in a community of learners. In K. McGilly (Ed.), Classroom lessons: Integrating cognitive theory and classroom practice (pp. 229-270). Cambridge, MA: MIT Press.

Driscoll, M. P. (2020). Psychology of learning for instruction (4th ed.). Boston: Pearson.

Dryden, M. \& Fraser, B. J. (1998, April). The impact of systemic reform efforts in promoting constructivist approaches in high school science. Paper presented at the annual meeting of the American Educational Research Association, San Diego, CA.

Ennis, R. H., \& Millman, J., \& Tomko, T. N. (1985). Cornell Critical Thinking Tests (3rd ed.). Pacific Grove, CA: Midwest Publications.

Ernst, J., \& Monroe, M. (2006). The effects of environment-based education on students' critical thinking skills and disposition toward critical thinking. Environmental Education Research, 12(3/4), 429-443.

Fraser, B. J. (2012). Classroom learning environments: Retrospect, context and prospect. In B. J. Fraser, K. Tobin, \& C, McRobbie (Eds.), Second international handbook of science education (Vol. 2, pp. 1191-1239). Dordrecht: Springer.

Jonassen, D. (1994). Thinking technology: Toward a constructivist design model. Educational Technology, 34(3), 34-37.

Kesal, F. \& Aksu, M. (2005). Constructivist learning environment in English language teaching methodology II courses. Hacettepe University Journal of Education, 28(1), 118-126.

Kline, R. B. (2011). Principles and practice of structural equation modeling (3rd ed.). New York: Guilford Press.

Kwan, Y.W. (2020). Psychometric properties of a Chinese version of the Constructivist Learning Environment Survey among secondary-school students in Hong Kong. Learning Environments Research, 23, 167-184.

Mathews, S. R., \& Lowe, K. (2011). Classroom environments that foster a disposition for critical thinking. Learning Environment Research, 14(1), 59-73.

McNichols, T. J. (1999). Deconstructing constructivism: The Kantian connection. Journal of Philosophy and History of Education, 49, 141-146.

Rumpagaporn, M. W. (2007). Students' critical thinking skills, attitudes to ICT and perceptions of ICT classroom learning environments under the ICT schools pilot project in Thailand (Doctoral dissertation). http://adt.caul.edu.au/. Accessed 6 March 2012.

Taylor, P. C., Fraser, B. J., \& White, L. R. (1994, April). CLES: An instrument for monitoring the development of constructivist learning environments. Paper presented at the annual meeting of the American Educational Research Association, New Orleans, LA.

Yang, Y., Newby, T., \& Bill, R. (2005). Using Socratic questioning to promote critical thinking skills through asynchronous discussion forums in distance learning environments. American Journal of Distance Education, 19(3), 163-181.

Yilmaz, K. (2008). Constructivism: Its theoretical underpinnings, variations, and implications for classroom instruction. Educational Horizons, 86(3), 161-172. 